\title{
ESCOLA ÚNICA DO TRABALHO PÓS-REVOLUÇÃO RUSSA DE 1917 E O TRABALHO COMO PRINCÍPIO EDUCATIVO
}

\author{
ESCUELA ÚNICA DEL TRABAJO POST-REVOLUCION RUSA DE 1917 Y EL TRABAJO \\ COMO PRINCIPIO EDUCATIVO EN LA
}

\section{SCHOOL OF WORK POST RUSSIAN REVOLUTION IN 1917 AND WORK AS EDUCATIVE PRINCIPLE IN THE ONLY}

\author{
Valter de Jesus Leite \\ Liliam Farias Porto Borges
}

\begin{abstract}
Resumo: Nos marcos dos cem anos da revolução Russa de 1917, objetivamos, neste artigo, indicar elementos que integraram a experiência da Escola Única do Trabalho pós-revolução Russa (1917-1931). Para tal, recorremos a um estudo bibliográfico, que tem por base, essencialmente os escritos de Pistrak, Lunatcharski, Krupskaia, Shulgin, Lenin, Freitas, Saviani e os Programas Oficiais da Educação na República dos Soviets. Destacamos, a partir desses estudos, que construir os embriões da sociedade socialista é educar e agir nas contradições das condições e das determinações da sociedade capitalista na atualidade com vistas à transformação social.
\end{abstract}

Palavras-chave: Pedagogia Socialista, Escola do Trabalho, Trabalho como princípio educativo.

Resumen: A los cien años de la revolución rusa de 1917, este artículo pretende indicar elementos que integraron la experiencia de la Escuela Única del Trabajo post-revolución rusa (1917-1931). Para ello, recoremos a un estudio que se basa, esencialmente, en los escritos de Pistrak, Lunatcharski, Krupskaia, Shulgin, Lenin, Freitas, Saviani y los Programas Oficiales de la Educación en la República de los Soviets. Destacamos, a partir de esos estudios, que construir los embriones de la sociedad socialista es educar y agir bajo las contradicciones de las condiciones y de las determinaciones de la sociedad capitalista actual con vistas a la transformación social.

Palabras-clave: Pedagogía Socialista, Escuela del Trabajo, Trabajo como principio educativo.

Abstract: At the milestone of 100 years from the Russian revolution in 1917, our goal in this article is to indicate elements that integrate the experience of the Only School of Work post Russian revolution (1917-1931). In order to do that we used a bibliographical study based mainly on Pistrak, Lunarcharski, Kruoskaia, Shulgin, Lenin, Freitas, Saviani and the Education Official Programs in the Soviet Republic. From these studies we highlighted that to build the embryos of the socialist society is to educate and act in the contradictions of the conditions and of the capitalist society determinations in the current days viewing the social changing.

Key-words: Socialist Pedagogy, School of Work, Work as educative principle

\section{O Papel da Educação na edificação da Republica dos Soviets}

A Revolução Russa de 1917 foi o primeiro e fecundo processo revolucionário socialista desencadeado num país atrasado com a estrutura societária e com as forças produtivas ainda num estágio semifeudal. O atraso econômico e social que antecedeu a 1917, ocasionado pelo poder absoluto dos tzares e pelos privilégios da nobreza e da Igreja, condicionou a existência de sérios problemas sociais, como a ausência de terra para os camponeses, a precariedade das condições de trabalho dos operários e a existência da fome. 
A Rússia contava com uma população de 67 milhões de pessoas, dessas, 23 milhões de servos sob o domínio de 103 mil proprietários. Mesmo com o decreto de 1861, que aboliu o regime de servidão, os lavradores, obrigatoriamente, compravam frações de terra (acerca de 5 hectares de terra por habitante masculino) pelo dobro de seu valor real, instituindo uma servidão econômica em lugar da servidão feudal, conforme Serge (1993).

O capitalismo avançou na Rússia em meio da existência da miséria da população do campo e da cidade e da insatisfação popular em fins do século XIX. Freitas (2009) afirma que contraditoriamente, em meio à fome, as exportações de cereais cresciam, e a abastança da burguesia se construía por meio da miséria do camponês e do proletariado.

Cerca de 79\% da população vivia no campo. Sendo que "em 1904, dez milhões de famílias camponesas eram detentoras de apenas 73 milhões de hectares de terra, entretanto 27 mil fundiários obtinham cerca de 62 milhões de hectares” (SERGE,1993, p.39). Em meio ao cenário de miserabilidade, a reivindicação primordial de $80 \%$ da população pobre do campo era o pão.

$\mathrm{Na}$ educação, existia um alto índice de população fora da idade escolar, a maioria dos operários e dos camponeses não tinham a oportunidade de frequentar o ensino formal, consequentemente, "três quartos da população eram analfabetos e os professores não estavam capacitados, tinham baixos salários e baixa posição social, ao passo que a Igreja Ortodoxa dirigia a maioria das escolas" (CASTLES E WUSTENBERG apud CIAVATTA, 2012, p.192).

Neste contexto, com a revolução de fevereiro de 1917, culminou na derrubada do czar e na instituição do Governo Provisório de Kerenski, dominado pela burguesia em ascensão e intimamente comprometido com a propriedade privada e com a manutenção da guerra. Desencadearam-se medidas, por meio do Programa e Constituinte, que se mostraram incapases de fazer frente à crise econômica e social. Concomitantemente, ressurgem os Sovietes (conselhos populares) constituídos por operários eleitos nas fábricas e nas cidades que lutavam pela distribuição das terras aos camponeses e exigiam o fim da guerra, conforme Serge (1993).

Com a efervescência política, a insurreição tomava conta de todo o país, os conflitos entre os dois poderes militares se agudizavam. De um lado, o governo provisório de Kerenski e, de outro, os Sovietes, de modo insurrecional. Essa tensão culmina numa longa luta resultando na tomada do poder pelos bolcheviques em outubro de 1917 e constituindo a efetiva revolução socialista. Os Sovietes foram fortalecidos e passaram a assumir a ofensiva e a ocupar locais estratégicos para construção do poder de Estado.

$\mathrm{Na}$ configuração da estratégia revolucionária em substituição aos antigos ministérios, criaram-se os comissariados do povo comandados pelos bolcheviques, que se fortalecem por meio da aliança operário-camponesa. O Comissariado do Povo para a Instrução Pública, também conhecido por Narkompros, foi instituído em 26 de outubro de 1917 para preocupar-se com toda a vida cultural, tendo por objetivo a reconstrução do sistema educacional para a formação do homem novo em consonância com a edificação da sociedade comunista. Anatoli Lunatcharski (1875-1933) presidiu esse comissariado no período de 1917 a 1929, seus membros eram Krupskaya (1875-1944), Lepshinsky (1868-1944) e Germinal: Marxismo e Educação em Debate, Salvador, v. 10, n. 3, p. 226-235, dez. $2018 . \quad$ ISSN: 2175-5604 227 
Pokrovsky (1868-1932) e foram responsáveis pela elaboração do documento "Princípios Fundamentais da Escola Única do Trabalho", que resultou na "Declaração sobre a Escola Única do Trabalho", aprovada pelo Comitê Central do Partido Comunista Bolchevique, em 30 de setembro de 1918.

Segundo Freitas (2009a) e Saviani (2012), com a criação do Narkompros, houve a constituição de uma Comissão Estatal Científica que comportou a Seção Pedagógica do Conselho Científico do Estado C.S.E., coordenada por Krupskaya, responsável pela elaboração dos programas de $1^{\circ}$ e $2^{\circ}$ Graus de 1923 e sua variante de 1927. Contribuíram na sua elaboração ainda Blonski (1884-1941), Shulgin (1894-1965), Pistrak (1888-1937) entre outros.

Os soviéticos tinham a percepção de que a edificação da sociedade comunista exigia a formação de um novo ser humano, e reconstruíram o sistema de ensino em consonância com o projeto societário revolucionário, com base e inspirados nos fundamentos educacionais decorrentes das proposições teóricas formuladas por Marx e Engels. Sabiam o quanto era necessário a transformação da escola no caminho da superação da forma escolar tzarista.

Krupskaia (s/d) enfatiza que a educação desempenha um papel crucial na transformação do ser humano, sendo que a educação politécnica se orienta pelo objetivo de propiciar a apropriação dos fundamentos científicos gerais dos processos de produção, de forma a contribuir com as novas relações entre os seres humanos pautadas pela coletividade e pela tentativa de abolir a separação do trabalho físico e intelectual.

Com base neste princípio de unificação entre teoria e prática, a Escola Única do Trabalho incorpora e apregoa uma pedagogia ancorada nas bases sociais e históricas, uma pedagogia que articula as bases da ciência com a dimensão do trabalho humano com vistas à reintegração do ser humano, historicamente comprometida pela divisão social do trabalho. Tratou-se de edificar uma educação na perspectiva da omnilateralidade em meio ao processo de construção da sociedade comunista.

A partir dessas diretrizes, Krupskaya salienta que os desafios apresentados nos primeiros anos constituiriam em eliminar e superar os “[... manuais impregnados da ideologia burguesa, ênfase em abordagens religiosas, chauvinismo, métodos adestradores, resistência reacionária do magistério [...] tudo que sabiam é que a velha escola tzarista-verbalista não lhes servia nesta nova caminhada" (PISTRAK apud FREITAS, 2009a, p. 11).

Entretanto, também tinham clareza que edificar a sociedade comunista exigira ter sujeitos com apropriação dos conhecimentos acumulados pela humanidade,

Por isso, ao condenar a antiga escola, propomo-nos tomar dela unicamente aquilo que
nos é necessário para conseguir uma verdadeira formação comunista. [...]. Seria errado
pensar que basta assimilar as palavras de ordem comunistas, as conclusões da ciência
comunista, sem assimilar a soma de conhecimentos de que o comunismo é
consequência. O marxismo é um exemplo que de como o comunismo resultou da soma
de conhecimentos adquiridos pela humanidade (LENIN, 1968, p. 97).

Desse modo, acreditava-se que se devia substituir o velho ensino livresco sem perder o acúmulo de conhecimentos que se encontrava na velha escola. No entanto, se fazia necessário o desenvolvimento das forças produtivas e a "[...] arte de assimilar toda a soma de conhecimentos humanos, e assimilá-los de 
tal modo que vosso comunismo não seja em vós algo aprendido de memória, mas algo pensado por vós mesmos [...]" (LENIN, 1968, p. 100-101).

Nesta direção, frente à problemática do analfabetismo, Lunacharsky, no Decreto sobre a educação popular de 11 de novembro de 1917, ao tratar do alto índice de analfabetismo e por ser a escola inacessível para uma proporção grande das crianças e jovens, dispõe que:

[...] debe trazar se como primer objetivo la lucha contra estas dos plagas. Debe, dentro de los plazos más perentorios, acabar enteramente con el analfabetismo organizando una red de escuelas que responda a las exigencias de la pedagogía moderna e implantando la enseñanza general obligatoria y gratuita; debe, al mismo tiempo, crear toda una serie de escuelas normales y establecimientos que puedan, a la mayor brevedad, formar el poderoso ejército de maestros necesarios para instruir a toda la población de la inmensa Rusia [...] (LUNACHARSKI, 1917, s/p).

$\mathrm{Na}$ Introdução aos Programas da Escola do $1^{\circ}$ Grau, ao tratar dos objetivos gerais da escola, Lenin (1968) anuncia que a escola soviética não visava somente fortalecer a luta contra a burguesia, mas ela se propunha a fortalecer a constituição da sociedade comunista. Lenin e os soviéticos compreendiam que a educação comunista jogava um papel essencial na construção da sociedade comunista, e que a escola, além de oferecer condições para a juventude identificar a necessária crítica à burguesia, tenciona, em sua tarefa, formar a consciência de classe e a faculdade de organizar as forças proletárias, como disposto nos Programas Oficiais (1935).

Ressaltamos que a Escola do Trabalho projetada especialmente por Shulgin, Pistrak, Krupskaia, Lunatcharski, entre outros, que integraram o Narkompros, foi a primeira a colocar, no crivo da prática, os fundamentos originários da teoria marxiana, construindo e reconstruindo teoricamente, a partir das práticas educativas em curso, o projeto educativo atrelado ao projeto societário comunista. Portanto, a finalidade das escolas soviéticas, neste período, era de criar coletivamente e na prática, a nova escola, dirigida pelos princípios básicos da escola única do trabalho.

\section{O trabalho como princípio educativo na Escola do Trabalho}

A Pedagogia Socialista Soviética, retomava o papel criativo e criador do trabalho enquanto valor de uso e socialmente necessário, no qual se converte, no âmbito da escola, em trabalho como princípio educativo. Pistrak (2000) na obra "Fundamentos da escola do trabalho", ao tratar do trabalho como princípio educativo, diz que é indispensável constituir a reunificação do ensino e da educação, por isso, “[...] é preciso passar do ensino à educação, dos programas aos planos de vida” (p.11), e, para tal, é imprescindível compreender o lugar e o papel do trabalho na escola soviética, uma vez que é inadmissível conceber o trabalho na escola sem que se considerasse os objetivos gerais da educação comunista.

A educação para os soviéticos era compreendida como ferramenta estratégica na construção da sociedade comunista e, logo, na luta contra a reação capitalista global e as próprias forças internas reacionárias. Ao se propor uma ruptura do modo de produção estavam convictos da necessidade de superar o sistema educacional burguês. Por isso, buscavam vincular o ensino com processos mais amplos de educação e de formação. Incorporavam o trabalho social no processo pedagógico de forma que 
estivessem conectados às reais contradições vivenciadas pela União Soviética. Compreendiam, conforme Lunatcharski (s/d, p.7) que a "[...] escola do trabalho deve ensinar todo mundo a trabalhar. Portanto, deve cuidar-se não só de fazer assimilar as matérias ensinadas por meio do trabalho, mas também ensinar às crianças o trabalho como tal”.

Pistrak (2000), ao tratar da problemática do trabalho na escola soviética depois de oito anos da declaração da Escola Única do Trabalho, identificava três vertentes e níveis de práticas a serem consideradas na tentativa de vincular o ensino ao trabalho. Entretanto, ao examinar essas vertentes, menciona que se limitam a conceber o trabalho como disciplina a ser estudada abstratamente, desconexa da vida e das suas contradições. Indicava, inclusive um certo simplismo na crença de que dedicando-se a trabalhos manuais por si só seriam apreendidos os conceitos e conteúdos sistematizados pela ciência e, ainda um alheamento em relação à realidade atual.

Da mesma forma como é impossível imaginar uma escola soviética isolada, separada da vida e situada nas condições ideais de uma ilha desabitada, também é impossivel imaginar o trabalho manual na escola a não ser como uma parte do problema geral do trabalho das crianças e dos adolescentes no sistema soviético, como parte do trabalho social. Se o problema é colocado dessa forma [trabalho separado da vida social, ou seja, sem considerar a realidade atual], a questão da relação entre o trabalho e a ciência perde todo o sentido ou, melhor dizendo, torna-se parte de um problema mais geral. O problema só podia ser colocado quando o ensino era separado da educação. Nossa escola deve liquidar esta separação. [...] não se trata de estabelecer uma relação mecânica entre o trabalho e a ciência, mas de torná-los duas partes orgânicas da vida escolar, isto é, da vida social das crianças (PISTRAK, 2000, p. 49-50. Grifos nossos).

Pistrak chamava a atenção para examinarmos o trabalho no âmbito da relação teoria e prática, com vistas a superar a dissociação entre essas duas dimensões. Sublinhava que o sentido da compreensão está na correlação da ciência com a vida social, entendendo essas duas dimensões articuladas organicamente e como parte de um processo educativo integral.

Percebemos que o trabalho é assim entendido como uma forma de envolver os estudantes na participação das lutas e contradições de seu tempo histórico concreto (atualidade), e a escola teria o papel fundamental de permitir que se compreenda o curso do desenvolvimento da história da sociedade humana, como aponta Shulgin (2013), “[...] a primeira concepção do princípio do trabalho é a de que a criança deve instruir-se por meio do trabalho, isto é, por métodos vivos, ativos” (LUNATCHARSKI, s/d, p.06). Dessa forma, podemos ver o trabalho como um princípio fundamental e a " [...] melhor forma de introduzir as crianças na vida laboral, ligar-se com a classe construtora, e não apenas entendê-la, mas viver sua ideologia, aprender a lutar, aprender a construir”" (SHULGIN, 2013, p. 41. Grifos do autor).

O trabalho que a Escola Soviética propõe a incorporar aos estudos não é o trabalho falseado normalmente realizado no interior da escola, mas conectar-se à "prática social, no meio social, entendendo-se a escola como continuidade deste meio e não como uma "preparação para este meio" como lugar onde se organiza a tarefa de conhecer este meio - com suas contradições, lutas e desafios" (FREITAS, 2009a, p. 35).

Constata-se que os soviéticos recuperaram o real sentido do trabalho no desenvolvimento humano e social, como trabalho produtivo no qual, independentemente do tempo histórico, define o 
modo humano de existir, criando e recriando o ser humano. Recuperam seu potencial formador para o caráter coletivo e a moral comunista, como meio de participação social, já que é o trabalho fundante da sociedade, nesta lógica.

Para o Narkompros, a articulação estudo - trabalho "implica a realização de atividades laborais e a compreensão dos processos produtivos (atuais e passados, dos diversos povos, considerando-se as experiências da localidade, da cidade, do país e do mundo, nos âmbitos material e não material" (SAVIANI, 2011, p. 37). Não se restringe aos trabalhos escolares, nem se trata somente da defesa da unificação entre trabalho e educação, mas sim de criar as condições para que a juventude assuma a luta em seu meio, para intervir, de forma criativa e criadora, perante as situações vivenciadas.

Deste modo, o trabalho socialmente necessário é o vínculo material entre estudo e trabalho, no qual assume um comprometimento social com a classe trabalhadora a partir de sua localidade, entretanto é necessário frisarmos que essa forma de "[...] trabalho social é um trabalho fora da escola [...] para ajudar os outros. [...] precisamente ele, rompe a limitação das escolas [...] introduz as crianças na sociedade mais ampla [...] e com eles ensina a resolver as tarefas do trabalho social" (SHULGIN, 2013, p. 142. Grifos do autor).

Podemos observar, que esta concepção amplia em muito a perspectiva comumente utilizada erm nossa contemporaneidade, para a ideia de vinculação entre trabalho e eeducação. O trabalho - na perspectiva da escola revolucionária russa - tem um valor social na medida que favorece a seleção e a preparação, por exemplo, das sementes que chegarão para a coletividade por meio das cooperativas, o que beneficiará a população no cultivo destes grãos, logo, contribuirá na organização e na edificação da sociedade comunista. Seu valor pedagógico localiza-se no próprio desenvolvimento do trabalho, e se desenvolve para o estudo dos procedimentos técnicos e científicos, por meio do estudo das máquinas, dos grãos, da sua qualidade e da germinação que envolvem processos de pesquisa, de análise e de investigação.

O Programa oficial (1935) considera a necessidade de constituir processos de aproximação dos estudantes com o trabalho, fator que pode ocorrer naturalmente pela vivência no meio, mas a escola necessita oferecer o teor pedagógico para a observação orientada já que, desde muito tempo, são objetos e práticas conhecidas da criança. Afinal ela chega à escola tendo aprendido a comer, a falar, a vestir-se, agora deve aprender a trabalhar.

Os programas devem conter, portanto, "[...] a observação e o estudo do trabalho humano" (p.97). Com isto, direcionam o estudo do trabalho, a partir de três processos: “1) Observação investigadora e estudo do trabalho humano dos adultos; 2) Participação das crianças, segundo suas possibilidades, nesse trabalho; 3) Exercícíos sistemáticos e treinamento em processo de trabalhos mais complexos" (PROGRAMAS OFICIAIS, 1935, p. 99).

Por isso o trabalho socialmente necessário e o seu vínculo com os programas da escola deve ocorrer de forma planejada para assegurar a relação com os conhecimentos que o requerem, então, deve, necessariamente, ser organizado em diferentes fases de sua realização, “1) o trabalho planejado, o plano; 2) propaganda entre a população; 3) preparação para sua realização (habilidades, conhecimentos adicionais, aquisição do equipamento etc.); 4) o próprio ato de execução; 5) avaliação” (SHULGIN, 2013, p. 151). 
Pistrak sublinha que o germe do politecnismo encontra-se nas relações de trabalho no campo devido às novas tecnologias introduzidas para manuseio da agricultura naquele contexto, declara, ainda, que:

[...] na escola do campo (e, portanto, definitivamente devem) organizar nelas um trabalho educativo em ramos específicos da agricultura que técnica e culturalmente sejam superiores àquele tipo de economia do entorno das escolas. [...] não apenas no sentido do nível cultural, mas também em termos de nível econômico da tecnologia, podem por muito tempo ainda estar acima do nível geral das pequenas unidades agrícolas das aldeias e isso, naturalmente, deve refletir de alguma forma na realização da educação politécnica nas escolas do campo (PISTRAK, 2015, p. 47).

Pistrak (2015), ao revelar o potencial do vínculo dos processos educativos no âmbito do politecnismo com as atividades produtivas do campo, anuncia que na realidade urbana (fábricas) o potencial é menor. Shulgin (2013) repudia essa tese e anuncia a necessidade de identificar, a partir do relatório do conselho da cidade e da sua economia, possibilidades para estreitar a escola e o trabalho.

[...] as tarefas atuais urbanas, as que estão postas perante a cidade. Os meios de produção da sua solução. É preciso que todas as escolas, urbanas ou regionais, dividindo-as em regiões, saibam o que podem fazer, o que podem assumir, e para isso cabe realizar um estudo adicional, um exame complementar (SHULGIN, 2013, p. 83).

Shulgin (2013) acreditava que a escola, no período de transição para a sociedade comunista, deveria caminhar para a extinção do abismo entre cidade e campo, afim de possibilitar aos estudantes a apropriação dos fundamentos tecnológicos e científicos imbuídos na produção fabril e agrícola, como possibilidade de "transferir pessoas da produção fabril para a aldeia e vice-versa" (SHULGIN, 2013, p. 206). Mesmo com a ausência das premissas necessárias para construir condições o mais rápido possível, as crianças e os jovens se familiarizariam com todo o sistema de produção. Referencia-se a Engels (1982) quando anunciava que a:

Assim a educação irá liberta-los da unilateralidade a que hoje os obriga a divisão atual do trabalho. [...] a sociedade organizada nos moldes comunistas vai permitir aos seus membros utilizar, sob todos os aspectos, as suas capacidades de modo multilateral. [...] Daí resulta que a contradição entre a cidade e o campo desapareça também (ENGELS apud SHULGIN, 2013, p. 84-85).

Portanto, a partir de Shulgin, compreende-se que seria preciso construir formas para desenvolver a educação em relação aos processos de trabalho com seus devidos potenciais no campo e na cidade. "As crianças da cidade devem poder orientar-se no sentido do meio e do trabalho agrícola, e as da aldeia bem conhecer o labor, as tendências e a luta do proletariado" (PROGRAMAS OFICIAIS, 1935, p. 105). Nem todas as escolas no campo e na cidade terão vínculos com as mesmas formas de trabalho num primeiro momento, devido às suas particularidades locais, mesmo que, num segundo momento ordem, seu vínculo com as formas de produção (campo e cidade) devam se materializar no trabalho educativo para superar a unilateralidade constituída pela cisão entre campo e cidade.

Embora a escola seja unitária em sua concepção, há uma escola para a população camponesa e uma escola para a população urbana as quais são desenvolvidas segundo suas ligações com o meio específico que cada uma tem. O sentido que o termo "trabalho" toma está materializado em cada meio, por sua cultura específica (FREITAS, 2009, p. 33-34). 
A articulação estudo - trabalho "implica a realização de atividades laborais e a compreensão dos processos produtivos (atuais e passados, dos diversos povos, considerando-se as experiências da localidade, da cidade, do país e do mundo, nos âmbitos material e não material)" (SAVIANI, 2011, p. 37). Não se trata somente da defesa da unificação entre trabalho e ensino, mas sim de como, se favorecerá a juventude para luta em seu meio, para intervir, de forma criativa e criadora, perante as situações vivenciadas (FREITAS, 2009).

Em Pistrak (2009) presenciamos a relação da escola e do trabalho por meio da categoria autosserviço, que direciona as práticas mais simples das formas do trabalho doméstico, geralmente vinculadas às necessidades cotidianas da comuna. Pistrak salienta que, no autosserviço, “[...] há elementos extremamente valiosos de significação formativa, os quais se devem usar inteiramente" (PISTRAK, 2009, p. 219). Segundo ele, a existência do autosserviço tomou como direcionamento dois fatores: 1) a necessidade, causada pelas condições materiais de existência; e 2) o formativo ao transferir para as crianças trabalho de autosserviço pessoal ou para iniciativa e criatividade nos mutirões de fim de semana e trabalhos de massa.

A partir destes dois fatores, Pistrak (2009) apresenta inúmeras tarefas da comuna que são desenvolvidas pelos estudantes, por exemplo, na cozinha: serrar, cortar e armazenar lenha, descascar batatas, cortes de carne; na calefação do prédio: fornecimento de lenha, na cantina: divisão e distribuição da alimentação, lavagem de louça e das mesas, manutenção e limpeza; na limpeza do prédio: limpeza dos dormitórios e gabinetes.

Salienta que o desenvolvimento do autosserviço favorece “[...] criar a pessoa com aptidões coletivas, formar e desenvolver nela uma série de aptidões sociais e hábitos [...]” (PISTRAK, 2009, p. 216) que permitirão que as crianças e jovens pudessem se inserir em formas de trabalho mais complexas. Percebemos que o autosserviço é um nível de trabalho que envolve menos capacidade formativa, ainda que cumpra certo nível de visão social do trabalho coletivo.

Para Shulgin (2013), o autosserviço é “[...] é uma necessidade amarga, e só isso; mas devemos aplicá-lo de modo racional nas esferas da educação e formação. [...] é o trabalho menos produtivo, mais irracional e antiquado". Ou seja, este não é o tipo de trabalho que se objetiva alcançar somente, é insuficiente, mas é um nível de exercitação do trabalho na escola que necessita passar para níveis mais elevados de trabalho. Por este viés, os Programas Oficiais das Escolas de $1^{\circ}$ Grau indicam que:

As crianças, porém, não podem e não devem se prender por muito tempo a essas
formas simples de trabalho, que não servem senão como ponto de partida, para as
formas mais complexas e difíceis do labor humano. Esta passagem deve ser
progressiva, pois, a preparação deverá ser mais longa, precisamente por ser mais
complexa e mais profunda. As crianças observam ativamente e estudam uma forma definida do
trabalho socialmente útil, determinam sua necessidade social e cientifica, suas formas sociais e
econômicas, exercitam-se metodicamente, com o objetivo de poder, o mais cedo possivel, participar
efetivamente desse esforço dos adultos (PROGRAMAS OFICIAIS, 1935, p. 98. Grifos dos
autores).

Ao mencionar a passagem dos trabalhos mais simples aos mais complexos, esteprojeto educativo considera o tempo necessário para alcançar os objetivos respeitando a faixa etária do $1^{\circ}$ grau, 
mas gradualmente ampliando as exigências para apropriação de conhecimentos e formas de trabalhos mais elevados. Pistrak e Shulgin compartilham que "[...] uma escola que pretenda assumir a perspectiva politécnica precisa alargar a esfera do trabalho socialmente necessário" (CALDART, 2015, p. 208).

Esta é uma perspectiva bastante diversa da ideia da relação entre trabalho e educação de nossa atualidade, o que indica a riqueza da retomada da experiência histórica da revolução socialista soviética e os desafios enfrentados pelos sujeitos nela envolvidos.

Como conclusões provisórias, podemos dizer que, a pedagogia socialista soviética, compreende o trabalho como princípio educativo enquanto pressuposto ontológico e ético-político no processo de socialização humana, portanto, extrapola o âmbito de trabalhos pontuais no interior da escola. A síntese desafiadora das proposições de Pistrak e a formulação da educação por complexos de estudos, indicam caminhos de reflexão e práticas pedagógicas promissoras ao apresentar três dimensões complementares do trabalho enquanto elemento pedagógico na sua relação com o processo pedagógico escolar, certamente por agirem em dimensões e em sentidos distintos do ser humano, bem como por interferirem, de distintas formas, na realidade. Sendo, primeiramente, a incorporação do trabalho humano enquanto prática social, como objeto de estudo científico, artístico e de análise das contradições que perpassam o mundo do trabalho, recorrendo à historicidade dos fenômenos sociais e naturais para compreenderem as contradições e do devir, e progressivamente os estudantes se apropriarem da concepção materialista histórica-dialética do mundo. O segundo diz respeito a dimensão do autosserviço (trabalho simples), e o terceiro se desenvolve para a dimensão do trabalho socialmente necessário, aquele que é imprescindível para a coletividade e que tem valor pedagógico e social, que resulta em valor de uso, de produtos ou de serviços necessários à construção da sociedade socialista.

\section{Referências}

CALDART, R. S. Educação no MST e Projeto Educativo Socialista: Convicções e Desafios de Luta e Construção. II Encontro Nacional das Educadoras e dos Educadores da Reforma Agrária, setembro de 2015. (mimeo).

CIAVATTA, M; LOBO, R. Pedagogia Socialista. In: CALDART, Roseli et al. (org.) Dicionário da Educação do Campo, RJ/SP, EPSJV/Expressão Popular, 2012.

ENGELS, F. Princípios básicos do comunismo. Lisboa: Editorial Avante, 1982.

FREITAS, L. C. A escola única do trabalho: explorando os caminhos de sua construção. In: CALDART, R. S. (Org.) Caminhos para a transformação da Escola: Reflexões desde práticas da Licenciatura em Educação do Campo. São Paulo: Expressão Popular, 2010. (Cadernos do ITERRA n. 15).

A luta por uma pedagogia do meio: revisitando o conceito. In: PISTRAK, M. M. (Org.) A Escola-Comuna. São Paulo: Expressão Popular, 2009a.

2015.

Prefácio. In: PISTRAK, M. Ensaios sobre a escola politécnica. São Paulo: Expressão Popular,

FREITAS, C. R. O escolanovismo e a pedagogia socialista na União Soviética no início do século XX e as concepções de educação integral e integrada. - Cascavel, PR; UNIOESTE, 2009. [dissertação de mestrado]. 
LENIN, V. I. Tarefas das Juventudes Comunistas (Discurso Pronunciado no III Congresso da União das Juventudes Comunistas da Rússia.p.95-112. In: LENIN, V. I. Cultura e Revolução Cultural. Tradução Lincoln Borges Jr. Rio de Janeiro - Civilização Brasileira, 1968.

LUNATCHARSKI, A. A Educação na Rússia Revolucionária. s/d. Disponível em: http://www.gepec.ufscar.br/textos-1/teses-dissertacoes-e-tccs/a-educacao-na-russiarevolucionaria/at download/file Acesso em 07 de setembro de 2014.

Decreto sobre la a educación popular. In.

http://marxists.org/espanol/lunacha/obras/1917-11-11.htm.Acesso em 26 de abril de 2014.

PISTRAK, M. Fundamento da escola do trabalho. 1. ed. São Paulo: Expressão Popular, 2000.

A Escola Comuna. São Paulo: Expressão Popular, 2009.

Ensaios sobre a Escola Politécnica. São Paulo: Expressão Popular, 2015.

PROGRAMAS OFICIAIS. A educação na República dos Soviets. Trad. de Violeta Sandra. São Paulo: Companhia Editora Nacional, 1935.

SAVIANI, D. Marxismo, educação e pedagogia. In. SAVIANI, D; DUARTE, N (orgs.). Pedagogia Histórico-crítica e luta de classes na educação escolar. - Campinas, SP: Autores Associados, 2012.

SAVIANI, N. Concepção Socialista de Educação: a contribuição de Nadedja Krupskaya. Revista HISTEDBR On-line, Campinas, número especial, p. 28-37, 2011.

SERGE, V. O ano I da Revolução Russa. São Paulo: Ensaio, 1993.

SHULGIN, Viktor. Rumo ao politecnismo. São Paulo: Expressão Popular, 2013. 